\title{
A STUDY ON DIGITLIZATION OF EDUCATION THROUGH UNDERSTANDING ICT
}

\author{
*Dr. Bhawna
}

\section{Abstract}

It is years together, we are getting educated dayby-day. The process of just seating in classroom and learning will have extremity. There are several mediums \& resource of education. In modern days, diversifying technology is at the top. The digitization is the exact solution for simplicity of arranging methods .Great things are promised by technology with it also to transform how people collaborate and communicate with each other. Research for years on classrooms technology, its adoption into the particular field seems to be very little. A modern classroom is basically Information and Communication Technology based Classroom. This aims at converting traditional classrooms into interactive sessions by combining best hardware with syllabus-complaint, multimedia content. Education sector shall have drastic change. In many colleges computers will be heavily used by teachers and students. This article explores this theme and discusses how a digital classroom is basically an ICT based classroom solution, helping convert traditional classrooms into interactive sessions.

Keywords: ICT, Digital Classroom, Information, Communication, Technology, Classroom Response System, CRS.

\section{Introduction}

Information and communication technology (ICT) includes computers, the internet and electronic delivery systems such as radio, televisions and projectors and among others, and is widely used in today's education field. ICT tends to expand access to education. Through ICT learning occur anytime and anywhere Schools use a diverse set of ICT tools to communicate, create, disseminate, store and manage information. ICT has also become integral to the teaching, learning interaction, through such approaches as replacing chalkboards with interactive digital white boards using students own smart phones or another devices for learning during class time, and the "FLIPPED CLASSROOM" model where students watch lectures at home on computers and use classroom time for more interactive exercises. The widespread use of ICT in education is not just a coincidence. It is observed in all aspects of our life.

Reid (2013) studied on "Quality assurance, open and distance learning, and Australian universities" They found that determined online instructors moved through different phases of their online learning experience and their needs change at each stage. Furthermore considering educational leaders were responsible for the quality on line programs and instruction they needed to engage in professional development and experiment with online learning environments infrastructure and technologies.

Park et al (2009) investigated on ICT in science education. A quasi experimental study of achievement, attitudes towards science and carrier aspirations of Korean middle school students. The researchers found some evidence that ICT assists high achieving students and encourage enrolment in science.

Dalton (2016) conducted survey for investing three dimension virtual environments which based on practice for meaningful and authentic language use

Wolcott et al (2011) in their study 'Faculty participation: Motivations, incentives and rewards 'found that intrinsic motives, such as job satisfaction and trying new technology tools and teaching strategies, were the most influential factors in faculty decisions to get involved in online learning. They found that faculty wanted to 
Participate were influenced by extrinsic motivations such as monetary support, course release time, and tenure and promotion credit. Furthermore some universities who did not provide faculty release time to develop online course have had staff members do this work as with instructional designers' multimedia developers and technology experts.

\section{Phases of ICT}

There are 5 phases of ICT

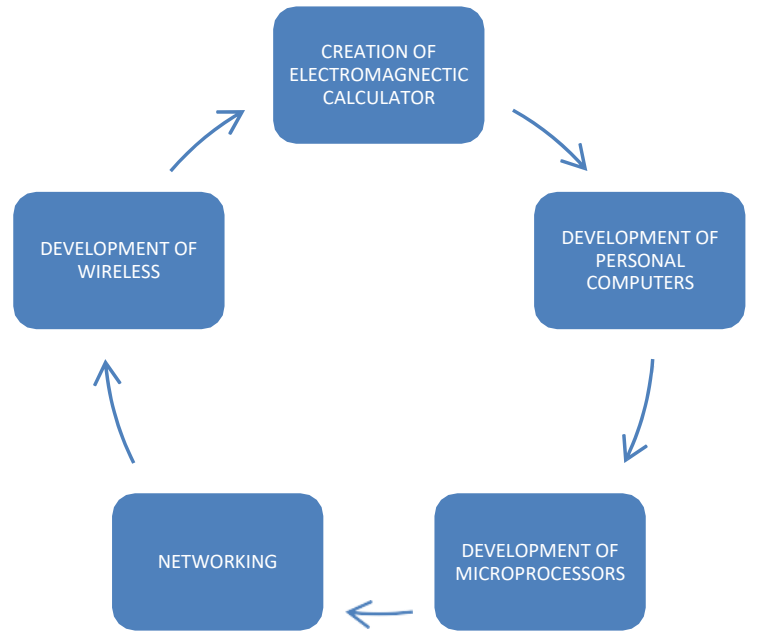

\section{Digital Classroom}

We are very well aware of Information and communication Technology (ICT). A digital classroom is basically an ICT-based classroom solution helping to convert traditional classroom into interactive sessions with the help of best hardware with syllabus complaint, multimedia content. Digitalization of classroom includes curriculum on digital content management and infrastructure and to support technology.

In a digital classroom, sets of computers are installed in classrooms and connected to the network. Classroom Response System (CRS) is a parallel method with digitized technology. There are two main of categories of CRSs, those that focus on rich digital ink input and those that rely on multiple choice or textual responses .The most feasible way to deploy CRSs in the classroom is to utilize the mobile devices that students already carry and to develop techniques to successfully integrate a diverse set of devices into the pedagogy for using CRSs.

In short the digitized classroom mean by

- Use of projector with tablet.

- Use of fewer papers.

- Use of digital resources and digital tools.
- Development of digital ethics and honor online, and respect for fair use for education.

- Teacher-collected or teacher-created resources.

- Inquiry, project \& problem based learning.

- Student work is published for a wider audience.

- Digital Literacy and Multimedia.

There are three important reasons to consider a Digital Classroom. These are as follows:

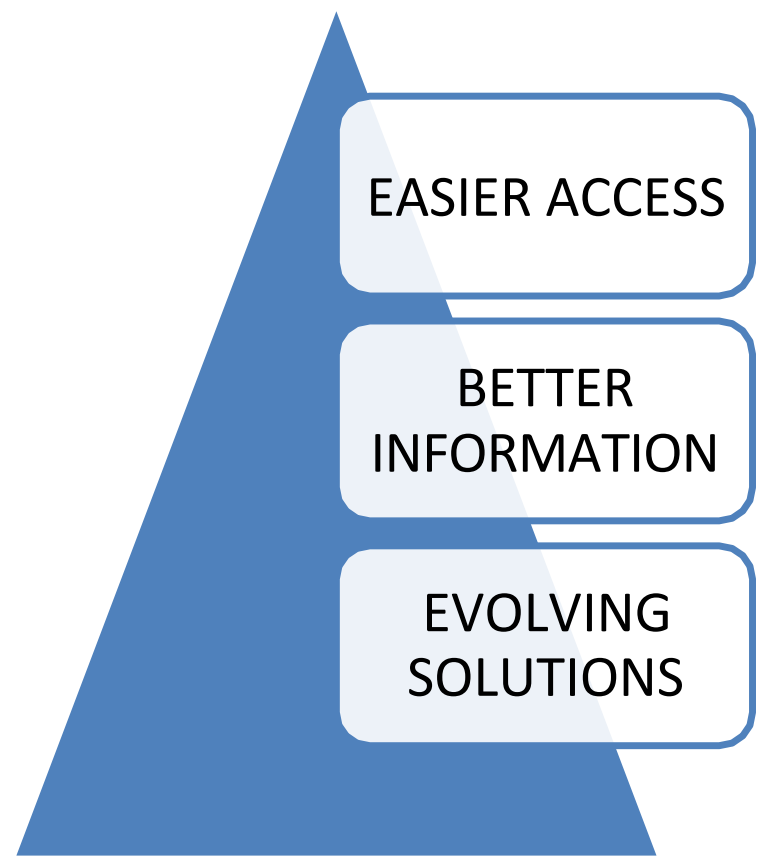

\section{Should Takeover/Long Way To}

Why to introduce technology into the classroom? Firstly, it can relive the burden on the instructor regardless of his /her skill level. Secondly, technology with its potential permits. Exposes good teachers to scale their abilities. This is to a larger audience and also reaches more people, more easily than with conventional classroom practices.

The universal major problem in implementing a digital classroom is cost. The facts are:

- The market for digitalization for classrooms touches the investment around Rs 1,500 crore in public schools and 2,5000 core in private schools.

- Its initiation and the demand is around $7,50,000$ classroom and at present only 80,000 classrooms are digitized. The classroom digitalization industry is growing at a rate of $50 \%$ year on year. Unfortunately, only $10 \%$ of the classroom are digitized in our country as of now. 
The market holders are using the powerful channel of 3D animation video to explain difficult concepts like formation of Block Mountain-
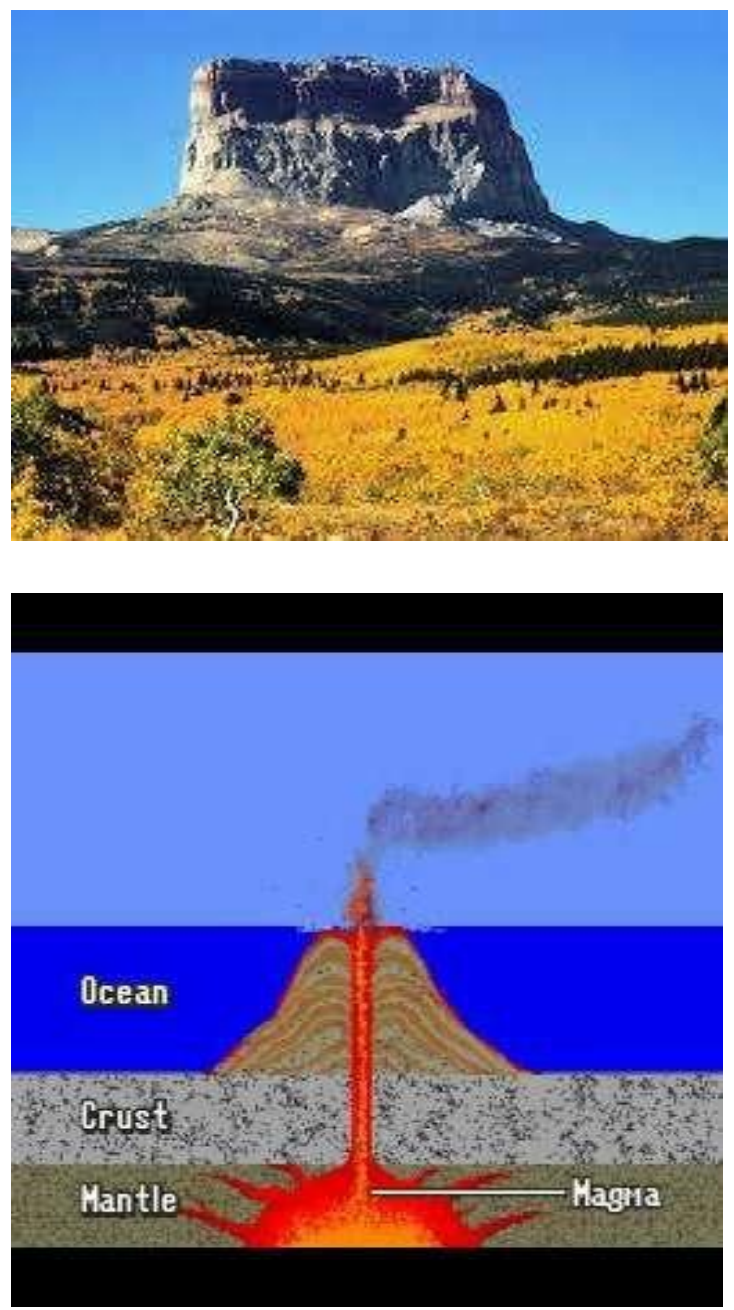

\section{Volcanic Formation}

From these types of pictures are using to clear the concepts of students. And Institutions are using the available technology to explain and simplify concepts in subjects like Chemistry, Physics, History, Biology and Science. Analysts expect this market to grow 10 times in next 5 years.

\section{Conclusion}

It totally depends on the Institution's decision of making all its classrooms in coming five years, otherwise the change will never happen. Converting every conventional classroom will be the solution and that too in effect, rather than aim for symbolic transition which may or may not happen depending on resources at the institutional level. It is definitely not the work of overnight. Coupling of proper and needed things will be a beginning. First is a qualified and stated intent to convert all classrooms with a cut-off date. Second is to create a clear roadmap to implement it.
The illiteracy, from a few years from now will be counted on the basis of unawareness of computer literacy despite having professional / non professional degrees and diplomas and that is because by then the rest of the world would have moved much ahead with digital education; our children despite having completed higher education will be left behind. Although will all the major challenges, we hope that the digital form of education reaches every school child in every small town of India. Because, that is where it is needed the most!

It is obvious that the availability and facilities provided by new ways of learning for both the student and the teacher. There will be shared working space and resources better access to information, promotion of collaborative learning and new discoveries.

Experts say in states like Tamil Nadu, Andhra Pradesh and Punjab, the acceptance for digital classrooms is also high. Among the major players in the organized sector are Educomp solutions, NIIT Everson systems, CompuCom, Class teacher Learning Systems, Tata Interactive systems (TIS) and Birla Shloka Edutech. Thus it is this digital aged time to grip the digital classroom.

\section{References}

1. Dutta, Diksha. "Time to teach the digital way". 2012; http://www.indianexpress.cpm/news/ time -to teach -the digital -way-/971867/41.

2. Ghosh, Debojyoti. "E-learning clicks with Indian schools ,but a long way to go", 2012; http:// www.indian express.com/news/ elearning-clicks with Indian schools but-a long -way-to-go /1004690/3.

3. Agarwal, Nidhi; Pundir, Neelam. A Study of Personality Traits of B.Ed. Students. Learning Community - An International Journal of Educational and Social development, 2016, $7(2)$, pp 127-131; doi: 10.5958/2231458X.2016.00013.0.

4. Agarwal, Nidhi; Gupta, Ruchika. "Role of Technology for the Efficiency of HR Management" Information and Communication Technology: Challenges \& Business Opportunities. (Eds. Singh Avinash; Kumar, Puneet; Kumar, Suresh) Excel India Publishers, Delhi, 2011, 174-176; ISBN:978-93-81361-00-9.

5. Bally, Ani. "Digital Classroom - legal education, 2012; http :// edudemic .com/2012/ 07/digital-classroom /(-01/02/2013.). 